\title{
LO QUE PIDEN LOS AGRICULTORES Y LO QUE PUEDEN LOS GOBIERNOS ¿MENDIGAR DEPENDENCIA O PROPORCIONAR EMANCIPACIÓN?
}

\section{WHAT FARMERS ASK FOR AND WHAT GOBERTMENTS CAN PROVIDED ¿PLEAD DEPENDENCE OR PROVIDE EMANCIPATION?}

\section{Lacki Polan}

Rua Bispo Dom José, 2051 apto 706

(55-41) 3243-2366 Celular: (55-41) 9602-1239. 80440-080 Curitiba - Paraná - Brasil

E-mails: Polan.Lacki@uol.com.br y Polan.Lacki@onda.com.br

Websites: www.polanlacki.com.br y www.polanlacki.com.br/agroesp

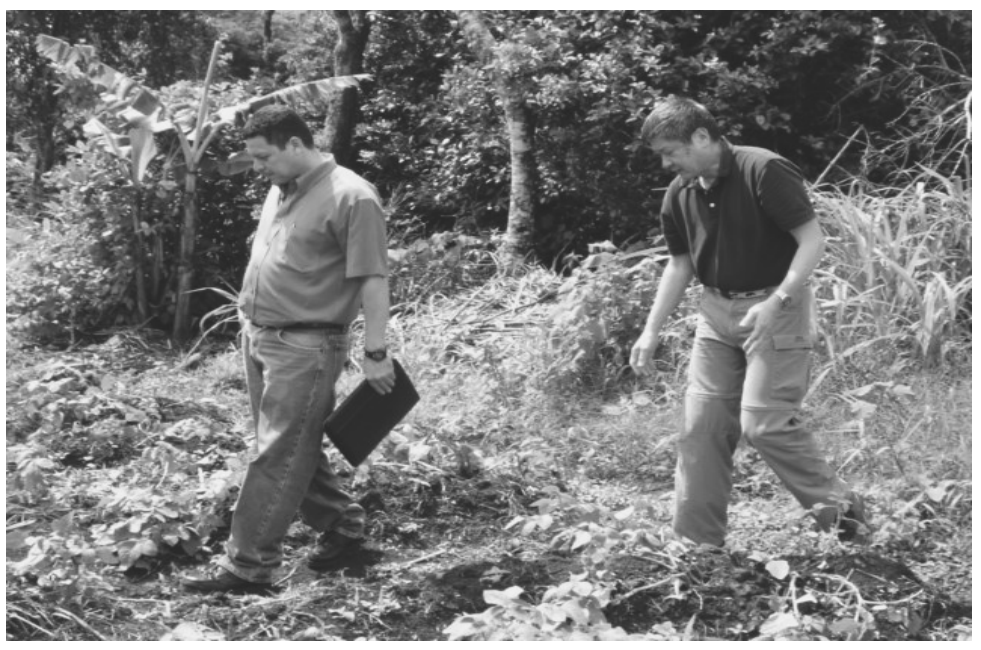

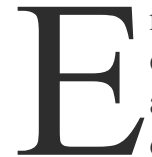

n los países de América Latina existe un evidente y creciente desequilibrio entre:

a) las múltiples y urgentes necesidades de millones de agricultores (quienes con todo el derecho reclaman tierra suficiente, riego, maquinaria, insumos modernos, crédito, garantías de comercialización, subsidios, etc.); y

b) las decrecientes posibilidades de los debilitados, deficitarios y endeudados gobiernos en satisfacerlas.

Como si esto fuese poco, los escasos recursos que los gobiernos destinan al agro, se vuelven aún más insuficientes porque suelen ser asignados en forma contraproducente a alimentar burocracias improductivas y a "regalar el pescado, año tras año en vez de enseñar a pescarlo una única vez". Este pseudo paternalismo contribuye a perpetuar la dependencia que los agricultores tienen del Estado y con ello a agudizar aún más dicho desequilibrio.

Los gobiernos no quieren o no pueden? Ante este creciente desbalance entre "lo que piden los agricultores y lo que pueden los gobiernos", seguir formulando agotadas propuestas paternalistas - por mejores que sean las intenciones de quienes lo hagan - es una actitud que causa mas daño que beneficio a los agricultores. Tales propuestas desorientan a los productores, estimulan la pasividad y de hecho los engañan, al sugerirles que sigan esperando por recursos y decisiones que los gobiernos, aunque quisiesen, no podrían proporcionarles. Este "desbalance" es tan abismal que las propuestas convencionales perdieron su eficacia y vigencia. El modelo llegó a tal grado de agotamiento que ya no es posible recuperarlo; sencillamente hay que reemplazarlo por una estrategia educativo-emancipadora.

Con tal fin los gobiernos, conscientes de que "no están en condiciones de hacer todo por todos los agricultores siempre", inexorablemente tendrán que asumir un papel esencialmente emancipador de dependencias. Con este propósito deberán delegar a los propios agricultores gran parte de la solución de sus problemas, en vez de alimentar en ellos la nueva ilusión de que el mercado y las cadenas agroalimentarias (agribusiness) lo harán por los productores; porque el mercado y el agribusiness están preocupados en resolver los problemas suyos y no necesariamente los de los productores rurales.

Para preparar esta progresiva emancipación, los gobiernos deberán promover formas sencillas de organización empresarial de los agricultores y proporcionarles los conocimientos mínimos que ellos necesitan para que verdaderamente quieran, sepan y puedan:

a) asumir, en forma gradual, actitudes y roles más protagónicos en la eficiente solución de sus propios problemas; e 
b) incrementar la bajísima productividad/rendimiento de todos los factores de producción que ellos ya poseen, con el elemental propósito de que cada unidad de mano de obra, tierra, insumo, crédito, animal, o tractor - por el simple hecho de que es escasa, cara o insuficiente - produzca con más eficiencia una mayor cantidad de granos, tubérculos, frutas, hortalizas, forraje, carne, lana o leche; y especialmente de ingresos.

En otras palabras, el Estado moderno deberá proporcionar a los agricultores las competencias para que ellos puedan "producir más y mejor con menos recursos, con menos Estado y con menos expropiación del agribusiness"

Primero lo posible después lo deseable. Con este propósito emancipador los gobiernos deberían fijarse, pragmática y “realísticamente', dos grandes prioridades estratégicas:

$1^{\text {ra }}$ Prioridad: En el corto plazo, formar, capacitaro recapacitar agentes de asistencia técnica y extensión rural (ATER) para que tengan mucho mayor capacidad de contribuir a una rápida corrección de las ineficiencias tecnológicas, gerenciales y organizativas que ocurren en los distintos eslabones del negocio agrícola; porque es necesario que tengamos la honestidad y la humildad profesional de reconocer que son las distorsiones allí existentes (y no tanto la falta de políticas, leyes, créditos y subsidios) las principales causas de la falta de rentabilidad en la agricultura. Sin embargo, la formación y capacitación de este nuevo agente de ATER no deberá ser apenas teórica, urbana, ni desvinculada de los problemas reales y concretos que los agricultores enfrentan en su vida cotidiana. Habrá que hacerla directamente en terreno y en forma más práctica, de modo que, siguiendo el método de aprender a producir produciendo, adquiera el ingenio y la competencia para formular y ejecutar soluciones pragmáticas que sean compatibles con las circunstancias de los países REALES de América Latina. ¿Y qué es lo que caracteriza a estos países reales?

a) gobiernos debilitados y empobrecidos con mínimas posibilidades de subsidiar y financiar la modernización del sector agropecuario; y

b) agricultores endeudados que no tienen acceso al crédito para aliviar sus severas restricciones productivas, que producen con bajísimos rendimientos y que están expuestos a una permanente expropiación que les imponen varios eslabones del agribusiness, ya sea cuando adquieren los insumos o cuando venden sus cosechas.

Este nuevo extensionista dotado de sólidas y vivenciadas aptitudes técnico -empresariales tendrá que ser capaz de ingeniar soluciones a los problemas de estos agricultores "tal como son y con los recursos que realmente poseen". Tendrá que ser capaz de enseñar a las familias rurales a ganar dinero a través del camino que, en el marco de la globalización, es el único posible; es decir, enseñarles a ganar dinero comprando, produciendo, administrando, invirtiendo, procesando y comercializando con mayor eficiencia tecnológica, gerencial y organizativa. Fuera de esta vía realista ningún artificialismo - político, arancelario, crediticio, tributario o cambiario - será capaz de hacer económicamente viables a los agricultores.

Ante un Estado que, aunque no lo diga, nos envía clarísimas señales de que no va a financiar, subsidiar ni proteger al sector agropecuario, el sentido común y el realismo nos imponen como un requisito absolutamente imprescindible fortalecer y mejorar dramáticamente la capacidad de la asistencia técnica y de la extensión agrícola. Ella tiene que ser capaz de profesionalizar a los agricultores y de organizar sus comunidades - ya no con el arcaico propósito de hacer proselitismo político - sino con el claro y explícito objetivo de que dichas asociaciones brinden servicios y solucionen aquellos problemas que, por razones de escala, los productores no pueden y no deben enfrentar en forma individual. La extensión rural, que históricamente ha arrojado extraordinarios ejemplos de mística y de competencia profesional necesita mejorar aún más su productividad, su efectividad y su capacidad de obtener resultados y de solucionar problemas. Deberá ser capaz de cambiar las aptitudes y actitudes de los agricultores, transformando cada familia en protagonista de un auto-desarrollo progresivo, que genere en la propia finca los recursos necesarios para financiar la tecnificación de la agricultura. Ante la escasez y alto costo del crédito rural dicho desarrollo tendrá que estar sustentado principalmente en la correcta aplicación de soluciones que sean acordes a los recursos ya existentes en las fincas; y no a los inexistentes, que los mistificadores o ingenuos siguen diciendo a los agricultores que están disponibles en las arcas de los gobiernos. Este es el nuevo agente de ATER, público y privado, que los agricultores tienen el pleno derecho de exigir; y que las universidades y escuelas agrotécnicas tienen el deber de formarlo.

$2^{\text {da }}$ Prioridad: En el mediano plazo, hacer una profunda "revolución educativa" en las escuelas básicas rurales (del ler. al $8^{\circ}$ año), incluyendo en sus curricula temas útiles y prácticos sobre producción agrícola, organización comunitaria, "asociativismo", administración rural, educación familiar, etc. Sus contenidos educativos deberán responder a las necesidades de vida y de trabajo imperantes en el campo; en vez de seguir aburriendo a los niños con memorización de fechas y nombres irrelevantes, con la historia del Imperio Romano y de los Faraones del Egipto o con otros temas lejanos, abstractos y totalmente divorciados de los problemas cotidianos que ellos viven y sufren en sus hogares, fincas y comunidades rurales; problemas que ellos no pueden y no podrán solucionar, entre otros motivos, porque la escuela no enseñó a hacerlo, ni a ellos ni a sus padres. La sociedad rural en vez de mendigar subsidios debe exigir al Gobierno que dichas escuelas contribuyan a desarrollar las enormes potencialidades latentes de los niños, a elevar su autoestima, a darles una sólida formación 
deseo de superación y proporcionarles conocimientos útiles que sean aplicables en la solución de sus propios problemas.

Estas dos medidas, de enorme y perdurable efecto transformador, contribuirían a emancipar a los agricultores de la dependencia del pernicioso y retórico paternalismo del Estado, en vez de perpetuarla. Debido a su sencillez y menor costo comparativo, cualquier gobierno podría llevarlas a la práctica.

Formar reivindicadores de soluciones o solucionadores de problemas?. Los créditos y los subsidios, por deseables o deseados que sean, son "perpetuadores" de dependencias porque hay que concederlos hoy, mañana y pasado mañana; y por este motivo adicional son insuficientes y excluyentes. En contraposición, el efecto de una educación instrumental que forme ciudadanos capaces de solucionar sus propios problemas en forma más autónoma, se perpetua en el tiempo sin necesidad de repetirla a las mismas personas año tras año. Los primeros son un gasto recurrente que perenniza una dependencia que el Estado no tiene capacidad de sostener en el tiempo y la segunda es una inversión que se hace una única vez y que construye la emancipación. Aquí ya no hay mucho que discutir, porque la segunda opción se impone por si sola; la agricultura latinoamericana está necesitando y exigiendo una inmediata y estratégica inversión en el recurso humano rural, a través de una excelente educación formal y no formal. En una primera etapa talvez no necesariamente con más educación y más inversiones en edificios y computadores; sino que con mejor educación, con contenidos más útiles, prácticos y relevantes que los egresados puedan utilizar en la solución de sus problemas cotidianos.

Con esta educación emancipadora un menor número de agricultores necesitará solicitar al Estado una menor variedad y cantidad de factores de producción y lo hará cada vez con una menor frecuencia. Una educación que ayude a las personas a que ellas mismas solucionen sus problemas es la única, repito única alternativa realista para reducir el desequilibrio mencionado al principio de este artículo. Esta opción permite que el Estado deje de alimentar frondosas burocracias que benefician a ALGUNOS y utilice estos recursos para cumplir con su deber de ofrecer una educación constructiva, útil y emancipadora para TODOS.

Definitivamente, la necesaria profesionalización de los agricultores requiere una imprescindible revolución en la calidad, utilidad y aplicabilidad de los contenidos educativos. Los "tractorazos y camionazos" que los agricultores han hecho, frente al Congreso Nacional, al Ministerio de Economía y al Banco Central no produjeron y difícilmente producirán resultados. Ellos deberán buscar las soluciones en los ministerios de educación y de agricultura y en sus similares a nivel provincial y municipal. Es allá donde los líderes rurales deberán exigir la formación y capacitación de extensionistas y agricultores acordes a los desafíos de la globalización, quienes, gracias a su mayor auto-confianza personal y auto-suficiencia técnica sean más solucionadores de problemas, que "reivindicadores" de soluciones.

En resumen, por más justo y legítimo que sea lo que actualmente piden los agricultores, ellos tendrán mucho más éxito si concentran sus reivindicaciones a lo que pueden y deben hacer los gobiernos. 